\title{
A Simple Five-Step Methodology to Determine Controllability of Heat Exchanger Networks Using Steady-State Information
}

\author{
Rodolfo Tellez, William Y. Svrcek and Brent R. Young, \\ University of Calgary, Department of Chemical and Petroleum Engineering; \\ e-mail: srtellez@ucalgary.ca,svrcek@ucalgary.ca and byoung@ucalgary.ca
}

\begin{abstract}
Process integration design methodologies have been developed and introduced to synthesise an optimum heat exchanger network (HEN) arrangement. However, controllability issues are often overlooked during the early stages of a plant design. In this paper we present a five-step procedure that involves the use of multivariable disturbance and control analyses based solely on steady-state information and with the purpose to assess process design developments and to propose control strategy alternatives appropriate and suitable for a HEN.
\end{abstract}

Index Terms-Disturbance analysis, heat exchanger network, heat-integration, multivariable control analysis.

\section{INTRODUCTION}

$\mathrm{T}$ HERE is an industrial and moral concern of having chemical plants that are environmentally sustainable and energy efficient over an wide range of operating conditions. Process design methodologies have been developed and introduced to meet lowestcost-of-operation and environmental constraints or demands leading to heat-integrated plant designs. However, controllability issues are often overlooked during the early stages of a plant design, and this problem may lead to extra work and extra cost for the resolution of possibly severe deficiencies in the ability to control the plant.

Many authors have discussed the importance of control systems design during the development of the design of a process (e.g. [1]) and it has been demonstrated that good control design is an effective way to ensure that a plant will exhibit flexibility for changes and resiliency to disturbances to operating conditions. This situation also applies for the design of a Heat Exchanger Network (HEN). HENs are the heart of heat-integrated plant designs and normally the classical synthesis of a HEN assumes and keeps all design operating conditions at a constant value, (e.g. [2]). Before further design for detailed engineering, some analysis and modifications of the synthesised HEN have to be carried out in order to guarantee good flexibility and resiliency of the HEN, since in reality operating conditions are expected to change. This implies the HEN works at different operating conditions, which are normally attained by changing set points in the control system.

The purpose of this paper is to present a simple and comprehensive procedure to determine the controllability of heat-integrated plants, in order to assess process design developments and to propose control strategy alternatives appropriate and suitable for a HEN. In this paper we present a five-step procedure to determine the controllability of a HEN using multivariable control and disturbance analyses based on steady-state information. This procedure can be easily implemented to assess both process design and control systems design. For the methodology presented in this paper, we assume a decentralized control system as the simplest approach to a multivariable control system for the HEN.

\section{STEADY-STATE INFORMATION}

First we need to determine the general plant gain matrix at steady state, $G_{P}^{G}$, which is an $m$ matrix, with the number of rows determined by the number of target temperatures $\left(\mathrm{TT}_{\mathrm{i}}\right)$ and the number of columns determined by the number of all potential cold and hot single and multiple bypasses $\left(\mathrm{Z}_{\mathrm{j}}\right)$. In general, $\mathrm{G}_{\mathrm{P}}^{\mathrm{G}}$ can be computed through the following equation:

$g_{P i j}^{G}=\frac{Z_{j}}{Z_{j}} T T_{i} \quad \frac{\Delta}{\Delta Z_{j}} T T_{i}$

$\mathrm{g}_{\mathrm{P} i j}^{\mathrm{G}}$ is the element ij of $\mathrm{G}_{\mathrm{P}}^{\mathrm{G}}$, representing the variation of the $\mathrm{i}$-th $\mathrm{TT}$ with respect to the variation 
of the $\mathrm{j}$-th potential bypass $\mathrm{Z}$ in the HEN. The information needed for $G_{P}^{G}$ can be obtained easily from steady-state models, dynamic models or process identification models.

The disturbance gain matrix $\mathrm{G}_{\mathrm{d}}$ of a HEN can be determined, as for $G_{P}^{G}$, from steady-state information, dynamic models or system identification data from the HEN. Each element of $G_{d}$ can be determined using the following formula:

$$
g_{d i k}=\frac{}{d_{k}} T T_{i} \quad \frac{d_{k}}{d_{k}} T T_{i}
$$

each $g_{d i k}$ element represents the variation of the i-th TT with respect to the variation of the $k$-th disturbance $d$ in the flow rate of each of the process streams and supply temperatures.

\section{SCALING OF VARIABLES}

The main objective of scaling variables is to keep them within the interval -1 and 1 , making easier the interpretation of the results for comparison of controllability indices, and ensuring stability of calculations. This normalization process depends on the process nature and the design requirements. The manipulated variables will be normalized with respect to their allowed range of variation, which normally will correspond to a physical constraint of the control valves that will be implemented on the real plant or availability of utilities or other process variables. The process variables will be normalized with respect to the allowed error range or offset in a feedback control system. Disturbances will be normalized with respect to their expected magnitude. A "“"will denote a scaled magnitude.

The scaling requires the set of operating rates and conditions. This is the knowledge of not only the nominal values of the process stream flow rates, heat capacities, supply and target temperatures, but also their expected variations.

\section{Five-Step Procedure}

The following is the five-step procedure developed in this paper to determine the controllability of a HEN.

\section{A. Step 1. Control Objectives}

For a HEN the most important control objective is to keep the Target Temperatures (TT) at the specified set points, or within acceptable ranges around the set points, thus guaranteeing proper downstream operation. The best option is "perfect control", i.e. control at the set point. However, depending on the downstream process requirements, a range of variation for acceptable control has to be determined.

Bypassing process-to-process heat exchangers will be done in order to control the TTs. The flow rates through such bypasses will be considered as the manipulated variables. Most important is to determine the appropriate set of hot and cold bypasses, single or multiple, needed to control TTs. We are not considering the control of TTs achieved by using process-to-utility heat exchangers, because the overall design of a HEN has to assume enough available utilities for all operating conditions.

\section{B. Step 2. Select Appropriate Bypasses}

The potential pairings can be determined through the use of the non-square Relative Gain Array (nsRGA). The ns-RGA was found to be an adequate tool to determine the needed pairings between single and multiple bypasses and target temperatures [3]. The way this ns-RGA will be formulated is described in the following array for a number $\mathrm{m}$ of $\mathrm{TT} s \mathrm{TT}_{1}$ to $\mathrm{TT}_{\mathrm{m}}$ and a number $\mathrm{n}$ of potential bypasses $Z_{1}$ to $Z_{\mathrm{n}}$. The ns-RGA can be evaluated using the following formula:

$$
{ }_{H E N}=G_{P}^{G} \quad\left[G_{P}^{G \dot{\dagger}}\right]
$$

where is the Schur product between two matrices and $\mathrm{G}_{\mathrm{P}}^{\mathrm{G}^{\dagger}}$ is the pseudo-inverse matrix of $\mathrm{G}_{\mathrm{P}}^{\mathrm{G}}$, calculated by using equation (4).

$G_{P}^{G \dot{\dagger}}=\left(G_{P}^{G}\right)^{T}\left[G_{P}^{G}\left(G_{P}^{G}\right)\right]^{1}$

The rank of ${ }_{\text {HEN }}$ is $m \quad n$. In order to determine the appropriate pairings between bypasses and target temperatures, elements nearest to 1 have to be chosen and this will ensure that the pairing values in the square RGA [4] derived from the general ns-RGA will be positive and relatively close to one, in order to guarantee large process gains. Once the appropriate 
elements of ns-RGA are chosen, then a square RGA is calculated using the selected columns of each of the rows of the ns-RGA. Once the appropriate pairings are selected, a square RGA of the HEN, HEN, is calculated:

$$
{ }_{H E N}=G_{P} \quad\left[G_{P}^{-1}\right]
$$

$\mathrm{G}_{\mathrm{P}}$ is obtained by eliminating the columns in $\mathrm{G}_{\mathrm{P}}^{\mathrm{G}}$ of the inappropriate by-passes. Now the rank of HEN is $\mathrm{m} \mathrm{m}$. This resulting RGA will confirm that the appropriate pairing will have large positive values, but it will not guarantee values close to 1 . Using this procedure an exhaustive screening process is avoided and it is not necessary to screen a factorial number of potential alternatives.

\section{Step 3. Flexibility of a HEN}

\section{1) Condition number.}

Westphalen et al. [5] proposed to determine the controllability of a HEN based on the analysis of the condition number ( ). The value of is calculated using the gain matrix $G_{p}$. If this condition number is small, the HEN is considered to be more controllable than a HEN with a large .

$$
=\frac{-G_{P}}{-G_{P}}
$$

The singular values ${ }^{-} \mathrm{G}_{\mathrm{P}}$ and ${ }_{-\mathrm{G}_{\mathrm{P}}}$ can be determined from the singular value decomposition (svd) of $\mathrm{G}_{\mathrm{p}}$. A HEN with a large condition number is considered to be ill-conditioned (e.g. [6]).

\section{2) Performance relative gain array.}

In order to overcome the problem of one-way coupling that the RGA cannot assess, Hovd and Skogestad [7] introduced the concept of the performance relative gain array (PRGA), which is defined as follows:

$$
{ }_{H E N}=G_{P}^{\bullet+} G_{P}^{\bullet-1}
$$

where $\mathrm{G}_{\mathrm{P}}^{\cdot+}$ is a diagonal matrix, having the same diagonal values of the scaled matrix $G_{\mathrm{P}}^{\bullet}$. PRGA is a good measure of the performance of the decentralized control system on the HEN giving an idea of the magnitude of the controlled variables. An svd analysis on a PRGA is useful to determine the interaction direction in a HEN [8]. Set point changes coming in the direction of the maximum singular value will affect adversely the performance of the control system because of the magnitude of interactions.

\section{Step 4. Disturbance Analysis of a HEN}

\section{1) Disturbance acting on a HEN.}

In this case the analyses that will be presented here will focus on both scaled $G_{P}$ and $G_{d}$. Flow rate upsets and supply temperature variations are considered the most important disturbances acting on a HEN.

\section{2) Disturbance condition number.}

The disturbance condition number is interpreted as the ratio between the required manipulated variables values for disturbance rejection and the manipulated variables values needed if the same disturbance gain was aligned with the largest HEN gain direction. The disturbance condition number ${ }_{d k}$ for a disturbance $d_{k}$ can be calculated from the following equation:

$$
d_{k}=\frac{\left\|G_{P}^{\bullet-1} g_{d_{k}}^{\bullet}\right\|_{2}}{\left\|g_{d_{k}}^{\cdot}\right\|_{2}}-G_{P}^{\cdot}
$$

$\mathrm{g}_{\mathrm{d}_{\mathrm{k}}}^{\bullet}$ is the column of $\mathrm{G}_{\mathrm{d}}^{\bullet}$ corresponding to the disturbance $\mathrm{k}$. In the formula the 2-norm of a vector is being used and indicated redundantly. dk may vary between 1 and. The later limit is undesirable.

\section{3) Closed-loop disturbance gain.}

Skogestad and Hovd [9] introduced the concept of the closed loop disturbance gain (CLDG), and this is an indicator for the performance of the decentralized control with respect to disturbance rejection [10]. The CLDG is calculated via the following formula:

$$
{ }_{H E N}={ }_{H E N} G_{d}^{\bullet}=G_{P}^{\bullet+} G_{P}^{\bullet-1} G_{d}^{\bullet}
$$

where HEN is CLDG of a HEN. The CLDG is closely related to the relative disturbance gain [11]. And if the values of its elements are below 1, it is said that no control is needed since the difference between 
the set point and the TT will never exceed its bounds [10]. This implies no controller is needed. The CLDG and the PRGA have the same mathematical origin; both were derived at the same time. Through an svd analysis on the CLDG we can predict the magnitude and interaction direction of the disturbances in the HEN.

\section{E. Step 5. Resiliency of a HEN}

1) Magnitude of manipulated variables.

Constraints on the manipulated variables can bound the capability of the HEN to reject disturbances and track set point changes. It is also important to find the smallest possible changes in the manipulated variables needed to reject disturbances. One way to achieve this is to determine the specified control performance. For "perfect control", when the difference between the set point and the process variable or error is zero, the values of the manipulated variables for "perfect" disturbance rejection is calculated using the following formula:

$u=G_{P}^{\bullet-1} G_{d}^{\bullet}$

and considering each disturbance and the worst case scenario, when $\left|\mathbf{d}_{\mathrm{k}}^{\bullet}\right|=1$.

For "acceptable" control, and if there is no set point changes, it is possible to achieve $\|u\| \quad 1$ for any $\left\|d^{\bullet}\right\| \quad 1$. In the formula the infinite norm of a vector is utilised to determine is a manipulated variables reaches its maximum or minimum value. Mathematically it is required to solve the following optimization problem:

$U_{\text {min }}=\min _{z}\|u\|$

Subject to $\left\|G_{P}^{\bullet} u+g_{d_{k}}^{\bullet} d_{k}^{\bullet}\right\| \quad 1$

$\left|d_{k}^{\bullet}\right|=1$

$\left|\mathrm{d}_{\mathrm{k}}^{\bullet}\right|=1$ represents the worst-case scenario.

2) Resiliency index.

Introduced by Morari et al. [12], the resiliency of the HEN can be determined by the maximum disturbance range, also known as Resiliency Index
(RI), such that for a maximum disturbance range, feasible operation is achieved. The RI is mathematically denoted by the following:

$\left\|d_{k}^{\bullet}\right\| \quad R I_{k}$

Feasible operation is defined as an acceptable performance in spite of limitations on the manipulated variable $\|u\| \quad 1$. The RI is determined by using equations 11 and 12, increasing the magnitude of the disturbance until $U_{\min }=1$.

\section{Case Study}

The following case study is the HEN studied by Ahmad et al [13]. This is the case of three hot process streams, $\mathrm{H} 1, \mathrm{H} 2$ and $\mathrm{H} 3$, and two cold process streams, C4 and C5. The stream data is shown in Table 1. Figures 1 and 2 show the two HENs synthesized by Ahmad et al. [13] with all alternative cold and hot bypasses. HEN\#1 was designed using pinch-point technology, with a minimum temperature approach of $30^{\circ} \mathrm{C}$, and $\mathrm{HEN \# 2}$ was obtained from HEN\#1 after a continuous optimization design procedure by minimizing the heat transfer area. The following is the implementation of the 5-step procedure presented above.

TABLE 1.

CASE STUDY STREAM DATA

\begin{tabular}{cccc}
\hline \hline Stream & $\begin{array}{c}\text { WCp } \\
\left(\mathrm{kW} /{ }^{\circ} \mathrm{C}\right)\end{array}$ & $\begin{array}{c}\mathrm{TS} \\
\left({ }^{\circ} \mathrm{C}\right)\end{array}$ & $\begin{array}{c}\mathrm{TT} \\
\left({ }^{\circ} \mathrm{C}\right)\end{array}$ \\
\hline $\mathrm{H} 1$ & 22.85 & 159 & 77 \\
$\mathrm{H} 2$ & 2.04 & 267 & 80 \\
$\mathrm{H} 3$ & 5.38 & 343 & 90 \\
$\mathrm{C} 4$ & 9.33 & 26 & 26 \\
$\mathrm{C} 5$ & 19.61 & 118 & 118 \\
\hline \hline
\end{tabular}

\section{A. Step 1. Control Objectives}

Table 2 summarizes the control objectives for both HENs. The number of potential single and multiple bypasses available to control each of the target temperatures are indicated in Table 3. As expected, when the number of heat exchangers in the HEN increases, so will the number of potential bypasses.

TABLE 2. Control obJectives

\begin{tabular}{c|c}
\hline \hline HEN & TT \\
\hline$\# 1$ and $\# 2$ & $\mathrm{H} 2, \mathrm{H} 3$ and $\mathrm{C} 4$ \\
\hline \hline
\end{tabular}


TABLE 3.

NUMBER OF POTENTIAL MANIPULATED VARIABLES

\begin{tabular}{c|c|c|c|c|c|c|c}
\multicolumn{2}{c|}{ Single } & \multicolumn{2}{c|}{ Double } & \multicolumn{2}{c|}{$\begin{array}{c}\text { Triple or } \\
\text { more }\end{array}$} & \multirow{2}{*}{$\begin{array}{c}\text { Potential } \\
\text { sets }\end{array}$} \\
\cline { 2 - 7 } & Hot & Cold & Hot & Cold & Hot & Cold & \\
\hline HEN\#1 & 7 & 7 & 3 & 1 & 1 & 3 & 1098 \\
HEN\#2 & 5 & 5 & 2 & 1 & --- & 1 & 220 \\
& & & & & & & \\
\hline \hline
\end{tabular}

\section{B. Appropriate Set of Bypasses}

Based on a steady-state model for each HEN, Tables 4 and 5 show the process gain values for each HEN. The tables also show the ns-RGA for each of the HENs. The bolded and underlined values are the ones considered most appropriate for pairing and will be selected for the square process gain matrix and for further analyses.

1) Scaled process gain matrix and square RGA.

Since the HEN design procedure utilized by Ahmad et al. [13] did not consider the existence of bypasses, and the temperature dependence of the heat capacity and pressure drops, some adjustments in the heat exchanger areas have to be made, in order to meet the pinch-point temperatures for $\mathrm{HEN} \# 1\left(159^{\circ} \mathrm{C}\right.$ and $129^{\circ} \mathrm{C}$ ), and to meet the target temperatures attained by using process-to-process heat exchangers.

According to the expected variations in the operating conditions and in the target temperatures, we scale the process gain matrix of HEN\#1 multiplying by 0.1 and HEN\#2 multiplying by 0.15 . The meaning of such factor is that we expect $5^{\circ} \mathrm{C}$ of variation in the target temperature and 0.1 or 0.15 flow rate fraction in the bypass respectively. Flow rate fraction of 0.1 or 0.15 means that the maximum flow rate in the bypass is $20 \%$ or $30 \%$ of the flow rate in the process stream.

Table 6 shows the new gain matrices for the HENs. The addition of bypasses will affect the overall heat transfer area of each HEN, and for both HENs we assumed that the WCp for the HEN synthesis was considered at pinch point conditions. WCp decreases with temperature, thus cold streams require more energy to be heated and hot streams interchange less energy when they are cooled down. Therefore, more hot utilities are required and less cold utilities. More energy is required below the pinch point, and less energy is interchanged above the pinch point. We also have to consider pressure drops as they not only affect upstream pump duties and downstream operations, but also the expansion of both cold and hot streams will add some thermal inefficiency, and more hot utilities will be needed to meet the target temperatures. Table 7 shows the results for the square RGA of each HEN, confirming that the bypasses selected are appropriate to control the HENs.

TABLE 4 GAIN MATRIX AND NS-RGA FOR HEN\#1

\begin{tabular}{|c|c|c|c|c|c|c|c|}
\hline & \multicolumn{3}{|c|}{$\mathrm{G}^{\mathrm{G} \bullet}{ }_{\mathrm{HENH1}}$} & \multicolumn{3}{|c|}{$\begin{array}{r}\mathrm{G} \\
\mathrm{HENH1} \\
\end{array}$} & \\
\hline & $\mathrm{TT}_{\mathrm{H} 2}$ & $\mathrm{TT}_{\mathrm{H} 3}$ & $\mathrm{TT}_{\mathrm{C} 4}$ & $\mathrm{TT}_{\mathrm{H} 2}$ & $\mathrm{TT}_{\mathrm{H} 3}$ & $\mathrm{TT}_{\mathrm{C} 4}$ & \\
\hline $\mathrm{X}_{1}$ & 0.000 & 0.000 & -0.163 & 0.000 & 0.000 & 0.007 & \\
\hline $\mathrm{X}_{2}$ & 0.000 & 0.000 & 0.000 & 0.000 & 0.000 & 0.000 & \\
\hline $\mathrm{X}_{3}$ & 0.000 & 0.000 & 0.000 & 0.000 & 0.000 & 0.000 & \\
\hline $\mathrm{X}_{4}$ & 0.527 & 0.000 & 0.234 & 0.028 & 0.000 & 0.020 & $\ddot{0}$ \\
\hline $\mathrm{X}_{5}$ & 0.846 & 0.000 & -0.163 & 0.050 & 0.000 & 0.000 & $\begin{array}{l}\text { D } \\
\text { 心 }\end{array}$ \\
\hline $\mathrm{X}_{6}$ & 0.000 & 1.521 & 1.250 & 0.000 & 0.141 & 0.472 & $\stackrel{0}{2}$ \\
\hline$X_{7}$ & 0.000 & 0.571 & -0.295 & 0.000 & 0.007 & 0.018 & م \\
\hline $\mathrm{X}_{12}$ & 0.000 & 0.000 & -0.164 & 0.000 & 0.000 & 0.007 & \pm \\
\hline$\underline{X}_{45}$ & 3.318 & 0.000 & -0.320 & $\underline{0.816}$ & 0.000 & -0.02 & \\
\hline$\underline{\mathbf{X}}_{67}$ & 0.000 & 5.077 & -0.726 & $\overline{0.000}$ & $\underline{0.826}$ & 0.030 & \\
\hline$\overline{X_{123}}$ & 0.000 & 0.000 & -0.164 & 0.000 & $\overline{0.000}$ & 0.007 & \\
\hline$Y_{1}$ & 0.000 & 0.000 & -0.220 & 0.000 & 0.000 & 0.013 & \\
\hline$Y_{2}$ & 0.000 & 0.000 & 0.000 & 0.000 & 0.000 & 0.000 & \\
\hline$Y_{3}$ & -0.08 & -0.04 & -0.019 & 0.001 & 0.000 & 0.000 & \\
\hline $\mathrm{Y}_{4}$ & 0.173 & 0.000 & 0.080 & 0.003 & 0.000 & 0.002 & ల్ల \\
\hline $\mathrm{Y}_{5}$ & 0.822 & 0.000 & -0.158 & 0.047 & 0.000 & 0.000 & జี \\
\hline $\mathrm{Y}_{6}$ & 0.000 & 0.177 & 0.149 & 0.000 & 0.002 & 0.007 & 2 \\
\hline $\mathrm{Y}_{7}$ & 0.000 & 0.768 & -0.398 & 0.000 & 0.012 & 0.033 & 그 \\
\hline$Y_{46}$ & 0.172 & 0.177 & 0.229 & 0.004 & 0.002 & 0.017 & ن \\
\hline$Y_{157}$ & 0.839 & 0.782 & -0.783 & 0.025 & 0.005 & 0.113 & \\
\hline $\mathrm{Y}_{246}$ & 0.208 & 0.232 & 0.280 & 0.006 & 0.004 & 0.026 & \\
\hline$\underline{Y}_{1357}$ & 0.945 & 0.884 & -1.119 & 0.021 & 0.000 & $\underline{0.252}$ & \\
\hline
\end{tabular}

TABLE 5.

\begin{tabular}{|c|c|c|c|c|c|c|c|}
\hline & \multicolumn{6}{|c|}{ GAIN MATRIX AND NS-RGA FOR HEN\#2 } & \multirow{9}{*}{ 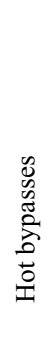 } \\
\hline & $\mathrm{TT}_{\mathrm{H} 2}$ & $\mathrm{TT}_{\mathrm{H} 3}$ & $\mathrm{TT}_{\mathrm{C} 4}$ & $\mathrm{TT}_{\mathrm{H} 2}$ & $\mathrm{TT}_{\mathrm{H} 3}$ & $\mathrm{TT}_{\mathrm{C} 4}$ & \\
\hline $\mathrm{X}_{1}$ & 0.000 & 0.000 & -0.16 & 0.000 & 0.000 & 0.002 & \\
\hline $\mathrm{X}_{2}$ & 0.000 & -0.26 & -0.13 & 0.000 & 0.001 & 0.001 & \\
\hline$\underline{\mathbf{X}_{\mathbf{3}}}$ & 8.667 & 0.000 & -1.69 & $\underline{\mathbf{0 . 8 6 0}}$ & 0.000 & -0.10 & \\
\hline$\overline{X_{4}}$ & 0.000 & 6.178 & 3.350 & $\overline{0.000}$ & $\underline{0.503}$ & 0.389 & \\
\hline$\overline{\mathrm{X}}_{5}$ & 0.000 & 1.311 & -0.66 & 0.000 & $\overline{0.070}$ & 0.059 & \\
\hline $\mathrm{X}_{12}$ & 0.000 & -0.31 & -0.30 & 0.000 & 0.000 & 0.005 & \\
\hline $\mathrm{X}_{45}$ & 2.167 & 1.808 & 0.218 & 0.049 & 0.042 & 0.005 & \\
\hline $\mathrm{Y}_{1}$ & 0.000 & 0.000 & -0.75 & 0.000 & 0.000 & 0.047 & \\
\hline $\mathrm{Y}_{2}$ & 0.000 & -0.20 & -0.1 & 0.000 & 0.001 & 0.000 & $\mathscr{W}$ \\
\hline $\mathrm{Y}_{3}$ & 3.715 & 0.000 & -0.70 & 0.160 & 0.000 & -0.02 & $\tilde{\Xi}$ \\
\hline $\mathrm{Y}_{4}$ & 0.000 & 0.498 & 0.281 & 0.000 & 0.003 & 0.003 & 官 \\
\hline $\mathrm{Y}_{5}$ & 0.000 & 2.086 & -1.05 & 0.000 & 0.177 & 0.017 & 르 \\
\hline $\mathrm{Y}_{24}$ & 0.000 & 1.111 & 0.593 & 0.000 & 0.017 & 0.012 & ن \\
\hline$\underline{Y}_{135}$ & 3.787 & 2.107 & -2.52 & -0.07 & 0.186 & $\underline{0.448}$ & \\
\hline
\end{tabular}

\section{Step 3. Flexibility of the HENs}

1) Calculate the condition number.

Table 8 shows the for each HEN. 
TABLE 6.

GAIN MATRIX FOR ALL HENS

\begin{tabular}{c|ccc|ccc|c}
\multicolumn{3}{c}{} & \multicolumn{3}{c|}{ HEN \#1 } & \multicolumn{3}{c|}{ HEN \#2 } & \\
\hline \multirow{3}{*}{$\mathrm{G}^{\bullet}$} & 3.461 & 0.000 & 0.957 & 6.199 & 0.910 & 0.000 & $\mathrm{TT}_{\mathrm{H} 2}$ \\
& 0.000 & 4.822 & 0.940 & 0.000 & 2.402 & 2.388 & $\mathrm{TT}_{\mathrm{H} 3}$ \\
& -0.41 & -0.87 & -1.15 & -1.13 & -1.49 & 2.023 & $\mathrm{TT}_{\mathrm{C} 4}$ \\
\hline \hline
\end{tabular}

TABLE 7.

RGA FOR ALL HENS

\begin{tabular}{c|ccc|ccc}
\hline \multicolumn{3}{c}{ HEN \#1 } & \multicolumn{3}{c}{ HEN \#2 } \\
\hline & 1.129 & 0.000 & -0.129 & 1.049 & -0.049 & 0.000 \\
& 0.000 & 1.194 & -0.194 & 0.000 & 0.606 & 0.394 \\
& -0.129 & -0.194 & 1.323 & -0.049 & 0.443 & 0.606 \\
\hline \hline
\end{tabular}

TABLE 8.

FOR EACH HEN

\begin{tabular}{c|c|c|}
\multicolumn{3}{c}{ FOR EACH HEN } \\
\cline { 2 - 3 } & HEN \#1 & HEN \#2 \\
\hline & 6.37 & 2.87 \\
\hline
\end{tabular}

2) Calculate PRGA and its svd values.

The PRGA for each HEN and its svd values are shown in Table 9, in order to determine the performance of the decentralized control system with respect to set point changes. HENs with the smallest variations will be preferred.

TABLE 9.

PRGA AND ITS SVD

\begin{tabular}{l|ccc|c}
\cline { 3 - 4 } \multicolumn{3}{c}{} & \multicolumn{5}{|c}{} & Maximum ii \\
\hline \multirow{3}{*}{ HEN\#1 } & 1.129 & 0.197 & 1.101 & \\
& 0.127 & 1.194 & 1.082 & 2.38 \\
& 0.155 & 0.237 & 1.323 & \\
\hline \multirow{3}{*}{ HEN\#2 } & 1.049 & -0.230 & 0.271 & \\
& -0.130 & 0.606 & -0.715 & 1.28 \\
& 0.110 & 0.334 & 0.606 & \\
\hline \hline
\end{tabular}

\section{Step 4. Disturbance Analysis}

\section{1) Determine HENs disturbance gain matrix and} scale it.

In Table 10 the scaled disturbance gain matrices, $\mathrm{G}_{\mathrm{d}}$, for each HEN are shown. The scaling factors for each of the disturbances are established according to their expected maximum variations. For disturbances in the flow rate, we expect a variation of $\pm 15 \%$ and for variations in the supply temperatures we expect a variation of $\pm 5^{\circ} \mathrm{C}$.
TABLE 10.

\section{SCALED GD FOR HEN\#1 AND HEN\#2}

\begin{tabular}{l|cccc|ccc}
\cline { 3 - 8 } & & \multicolumn{3}{c|}{$\mathrm{G}_{\mathrm{d}-\mathrm{HEN} \# 1}$} & \multicolumn{3}{c}{$\mathrm{G}_{\mathrm{d}-\mathrm{HEN} \# 2}^{\circ}$} \\
\cline { 3 - 8 } $\mathrm{d}_{1}$ & $\mathrm{TC}_{\mathrm{H} 2}$ & $\mathrm{TT}_{\mathrm{H} 1}$ & $\mathrm{TT}_{\mathrm{C} 4}$ & $\mathrm{TT}_{\mathrm{H} 2}$ & $\mathrm{TT}_{\mathrm{H} 3}$ & $\mathrm{TT}_{\mathrm{C} 4}$ \\
\cline { 3 - 8 } $\mathrm{d}_{2}$ & 0.07 & 0.06 & 0.18 & 0.00 & 0.07 & 0.09 \\
$\mathrm{~d}_{3}$ & $\mathrm{WCp}_{\mathrm{H} 2}$ & 1.50 & 0.00 & 0.51 & 1.47 & 0.00 & 0.95 \\
$\mathrm{~d}_{3}$ & $\mathrm{WCp}_{\mathrm{H} 3}$ & 0.00 & 1.88 & 1.10 & 0.00 & 2.92 & 0.57 \\
$\mathrm{~d}_{4}$ & $\mathrm{WCp}_{\mathrm{C} 4}$ & -1.35 & -1.30 & -1.24 & -0.83 & -2.05 & -1.84 \\
$\mathrm{~d}_{5}$ & $\mathrm{WCp}_{\mathrm{C} 5}$ & -0.08 & -0.15 & -0.33 & 0.00 & -0.22 & -0.19 \\
$\mathrm{~d}_{6}$ & $\mathrm{TS}_{\mathrm{H} 1}$ & 0.21 & 0.24 & 0.69 & 0.00 & 0.35 & 0.50 \\
$\mathrm{~d}_{7}$ & $\mathrm{TS}_{\mathrm{H} 2}$ & 0.35 & 0.00 & 0.07 & 0.53 & 0.00 & 0.41 \\
$\mathrm{~d}_{8}$ & $\mathrm{TS}_{\mathrm{H} 3}$ & 0.00 & 0.70 & 0.23 & 0.00 & 0.31 & 0.26 \\
$\mathrm{~d}_{9}$ & $\mathrm{TS}_{\mathrm{C} 4}$ & 1.06 & 0.85 & 0.37 & 1.48 & 1.11 & 0.48 \\
$\mathrm{~d}_{10}$ & $\mathrm{TS}_{\mathrm{C} 5}$ & 0.19 & 0.34 & 0.64 & 0.00 & 0.27 & 0.24 \\
\hline \hline
\end{tabular}

2) Calculate the disturbance condition number.

Table 11 shows the disturbance condition number, for each of the HENs. Disturbance condition numbers that are much less than are desired. Those close to are considered to be in a bad direction. By inspection, all disturbances have a considerable effect on the HEN.

TABLE 11.

DISTURBANCE CONDITION NUMBER

\begin{tabular}{c|c|c} 
& HEN\#1 & HEN\#2 \\
\hline d1 & 6.23 & 2.21 \\
d2 & 3.29 & 2.17 \\
d3 & 4.29 & 1.88 \\
d4 & 4.90 & 2.12 \\
d5 & 6.25 & 2.07 \\
d6 & 6.30 & 2.28 \\
d7 & 2.60 & 2.31 \\
d8 & 3.27 & 2.06 \\
d9 & 3.42 & 1.59 \\
d10 & 6.14 & 2.06 \\
\hline \hline
\end{tabular}

3) CLDG and its svd values.

Table 12 shows the values of the svd of the CLDG. Those having the least magnitude of effect will be preferred. Maximum effects have to be expected when disturbances in the flow rates occur.

TABLE 12.

SVD OF THE CLDG OF EACH HEN

\begin{tabular}{|c|c|c|c|}
\hline & HEN\#1 & HEN\#2 & \\
\hline Maximum ii & $\begin{array}{l}6.82 \\
3.74\end{array}$ & $\begin{array}{l}2.78 \\
1.83\end{array}$ & $\begin{array}{c}\text { WCp } \\
\text { TS }\end{array}$ \\
\hline
\end{tabular}

E. Step 5. Resiliency of the HENS

1) "Perfect" and "acceptable" control.

Table 13 shows the maximum value of the two manipulated variables in order to reject each and all of the disturbances to the HEN to have "perfect" 
control. If numbers are above 1 , then we have to consider that we only are able to have acceptable control. Also in Table 13 the maximum value of the manipulated variables to achieve "acceptable" control are shown in bold, italic and underlined, which mean that the target temperatures will have a variation within a range of $\pm 5^{\circ} \mathrm{C}$ from the specified set point value. If some of the values of $U_{\min }$ are greater than 1 that means that the bypass has no capacity to reject the disturbance and we might have a large offset.

TABLE 13.

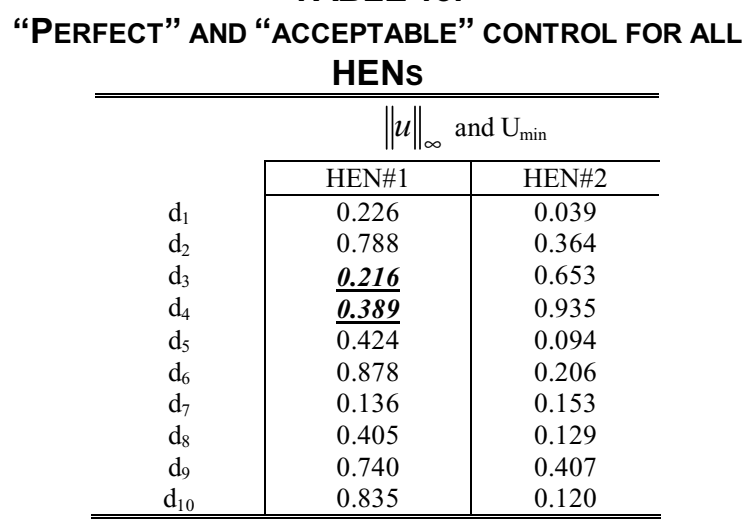

2) Resiliency indexes.

In Table 14 we present the values of the resiliency index for each of the HEN for each individual disturbance. Those HENs with the largest values will be preferred.

TABLE 14.

RESILIENCY INDEX FOR ALL HENS

\begin{tabular}{c|c|c} 
& \multicolumn{1}{c|}{ HEN\#1 } & HEN\#2 \\
\hline $\mathrm{d}_{1}$ & 11 & 39 \\
$\mathrm{~d}_{2}$ & 2.7 & 3.7 \\
$\mathrm{~d}_{3}$ & 1.29 & 1.99 \\
$\mathrm{~d}_{4}$ & 1.32 & 1.46 \\
$\mathrm{~d}_{5}$ & 5.8 & 14 \\
$\mathrm{~d}_{6}$ & 2.8 & 7.4 \\
$\mathrm{~d}_{7}$ & 13 & 9.0 \\
$\mathrm{~d}_{8}$ & 6.1 & 12 \\
$\mathrm{~d}_{9}$ & 3.4 & 3.8 \\
$\mathrm{~d}_{10}$ & 2.9 & 13 \\
\hline \hline
\end{tabular}

\section{F. Some Results from Dynamic Simulations}

By analyzing all the values presented in the above tables, we can determine that HEN\#2 is the most appropriate arrangement, because, overall, it presents the best values of all the controllability parameters. Dynamic simulation was then employed to validate this conclusion.

Figures 3 and 4 show the dynamic behaviour of
HEN\#1 and HEN\#2 respectively, due to set point changes of $5^{\circ} \mathrm{C}$. These figures confirm that set point changes will reveal large interactions in HEN\#1, compared to HEN\#2. Figures 5 and 6 show the dynamic behaviour to disturbances in $\mathrm{WCp}_{\mathrm{H} 3}$ and $\mathrm{WCp}_{\mathrm{C} 4}$. Disturbances will have a lower effect on the manipulated variables of HEN\#2 compared to HEN\#1. Moreover, some variations in HEN\#1 will result in offsets from the desired set points. Finally, Figures 7 and 8 show the dynamic behaviour due to disturbances in $\mathrm{TS}_{\mathrm{H} 2}$ and $\mathrm{TS}_{\mathrm{H} 3}$. As predicted above, disturbances in the supply temperatures will have a very low effect on both HENs and to much lower degree in HEN\#2. All of these figures confirm that HEN\#2 is the best choice.

\section{Some Process Design Considerations}

Without considering bypasses, the temperatures and heat duties of a HEN are based on the fact that the heat capacity changes with temperature, and also pressure drop across the network. We should not forget that for further analysis we have to consider the cost of the pipelines, including bypasses, control and manual valves, instrumentation and the control system.

The addition of bypasses will affect the heat transfer areas of all heat exchangers. In Table 15 the heat transfer areas of each heat exchanger in each HEN are shown. Another factor that affects the size of the heat exchangers is the fact that the flow rate splits have to be modified in order to meet the target temperatures.

\section{TABLE 15.}

\begin{tabular}{c|c|c|c|c}
\multirow{2}{*}{} & \multicolumn{4}{c}{ HEAT TRANSFER AREAS, IN $\mathbf{~}^{2}$} \\
\cline { 2 - 5 } & \multicolumn{2}{c}{ HEN\#1 } & \multicolumn{2}{c}{ HEN\#2 } \\
\cline { 2 - 5 } & $\begin{array}{c}\text { Without } \\
\text { bypasses }\end{array}$ & $\begin{array}{c}\text { With } \\
\text { bypasses }\end{array}$ & $\begin{array}{c}\text { Without } \\
\text { bypasses }\end{array}$ & $\begin{array}{c}\text { With } \\
\text { bypasses }\end{array}$ \\
\hline HX1 & 25.2 & 1.8 & 0.7 & 0.7 \\
HX2 & 6.5 & 6.5 & 60.2 & 8.0 \\
HX3 & 1.2 & 1.2 & 14.6 & 125.4 \\
HX4 & 11.7 & 6.0 & 33.6 & 82.5 \\
HX5 & 35.2 & 169.2 & 47.8 & 75.9 \\
HX6 & 23.2 & 21.2 & ---- & --- \\
HX7 & 47.8 & 918.3 & ---- & --- \\
CH1 & 11.7 & 11.7 & 11.7 & 12.5 \\
HC5 & 511.5 & 79.5 & 76.4 & 79.5 \\
\hline \hline
\end{tabular}

In order to optimize the total cost of a HEN, the size of the bypasses can be decreased based on the controllability results. From the "perfect" control analysis we can consider this possibility if the values 
of the manipulated variable, $\mathrm{u}$, or $\mathrm{U}_{\min }$ are small. For example, if the values are lower than 0.5 , we can consider to decrease at least a third of the original size considered for the analysis, allowing us to have enough flow rate to reject disturbances and economize in the size of the piping diameters of the bypasses, as well as of the control valves.

\section{CONCLUSIONS}

The above five step methodology using steady state controllability measures proved to be a useful screening tool to determine the controllability of a set of potential HEN for a particular plant. The magnitude of such measures can be used to determine the more controllable HEN. Dynamic simulations support the results obtained from this methodology. By keeping the methodology simple and practical, the hope is that it can be easily understood and exploited by process and control systems design engineers using commercial simulators, in the design of actual chemical processes.

\section{REFERENCES}

[1] W.L. Luyben, B.D. Tyreus, and M.L. Luyben, "Plantwide process control procedure", AIChE Journal, vol. 43, pp. 3161-3174, 1997.

[2] U.V. Shenoy, Heat Exchanger Network Synthesis. Houston, TX, Gulf Publishing Company, 1995.

[3] Y. Cao, "Control Structure Selection for Chemical Processes using Input-Output Controllability Analysis", PhD Thesis, University of Exeter, UK, 1995.

[4] E.H. Bristol, "On a new measure of interactions for multivariable process control", IEEE Trans. Auto. Con., AC-11, pp. 133-134, 1966.

[5] D.L. Westphalen, B. R. Young, and W.Y. Svrcek, "Strategies for the Operation and Control of Heat Exchanger Networks", in Proc. FOCAPO 2003, Coral Springs, FL, Jan. 12-15, 2003, pp. 425-428.

[6] D.E. Seborg, T.F. Edgar, and D.A. Mellichamp, Process Dynamics \& Control. John Wiley \& Sons, New York, 1989.

[7] M. Hovd, and S. Skogestad, "Simple frequencydependent tools for control system analysis, structure selection and design", Automatica, vol. 28, no. 5, pp. 989-996, 1992.

[8] P. Grosdidier, "Analysis of interaction direction with the singular value decomposition", Comp. \& Chem. Engng. vol. 14, no. 6, pp. 687-689, 1990.

[9] S. Skogestad, and M. Hovd, "Use of Frequency Dependent RGA for Control Structure Selection", in Proc. American Control Conference (ACC), San Diego, May, 1990, pp. 2133-2139.
[10] A.J. Groenendijk, A.C. Dimian, and P.D. Iedema, "Systems approach for evaluating dynamics and plantwide control of complex plants", AIChE Journal, vol. 46, no. 1, pp. 133-145, 2000.

[11] S. Skogestad, and E.A. Wolff, "Controllability measures for disturbance rejection", Modeling, Identification and Control, vol. 17, no. 3, pp. 23-51, July 1996.

[12] M. Morari, W. Grimm, M.J. Oglesby, and I.D. Prosser, "Design of resilient processing plants VII. design of energy management systems for unstable reactors - new insights", Chem. Eng. Sci., vol. 40, pp. 187-198, 1985.

[13] S. Ahmad, B. Linnhoff, and R. Smith, "Cost optimum heat exchanger networks -2 . targets and design for detailed capital cost models", Comp. \& Chem. Eng., vol. 14, no. 7, pp. 751-767, 1990.

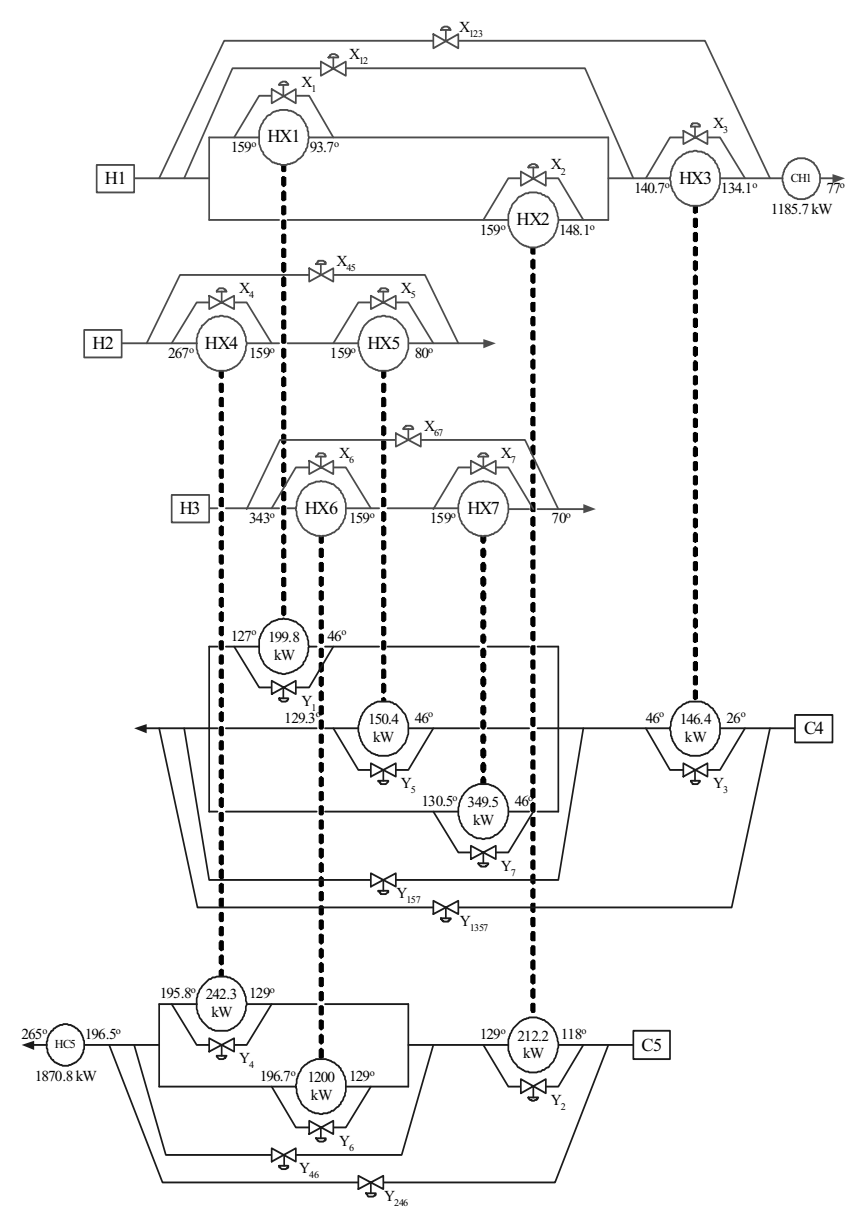

Fig. 1. HEN\#1 and all alternative cold and hot bypasses 


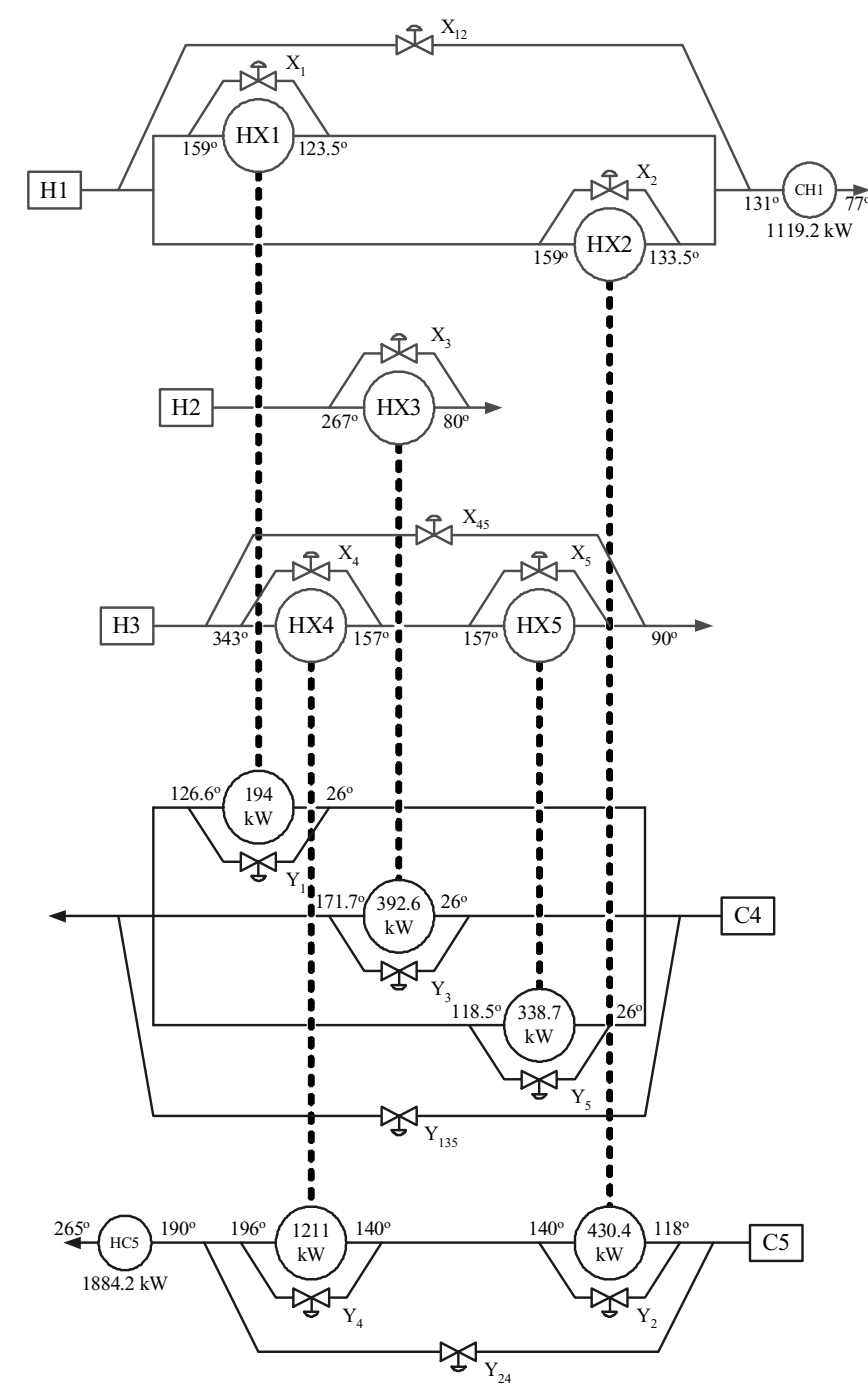

Fig. 2. HEN\#2 and all alternative cold and hot bypasses

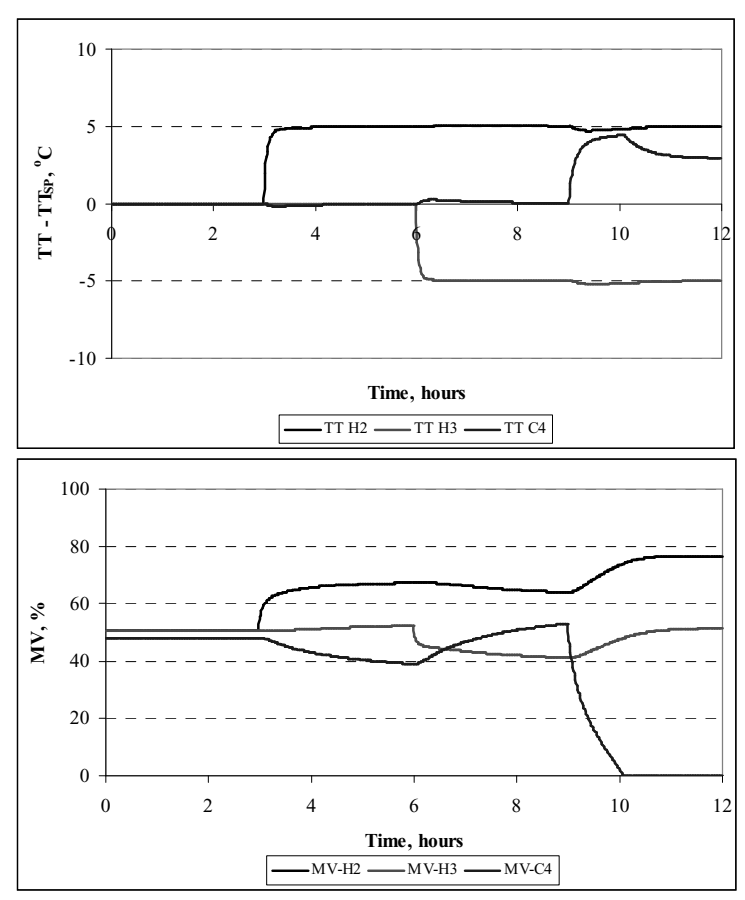

Fig. 3. Dynamic behaviour of HEN\#1 to set point changes
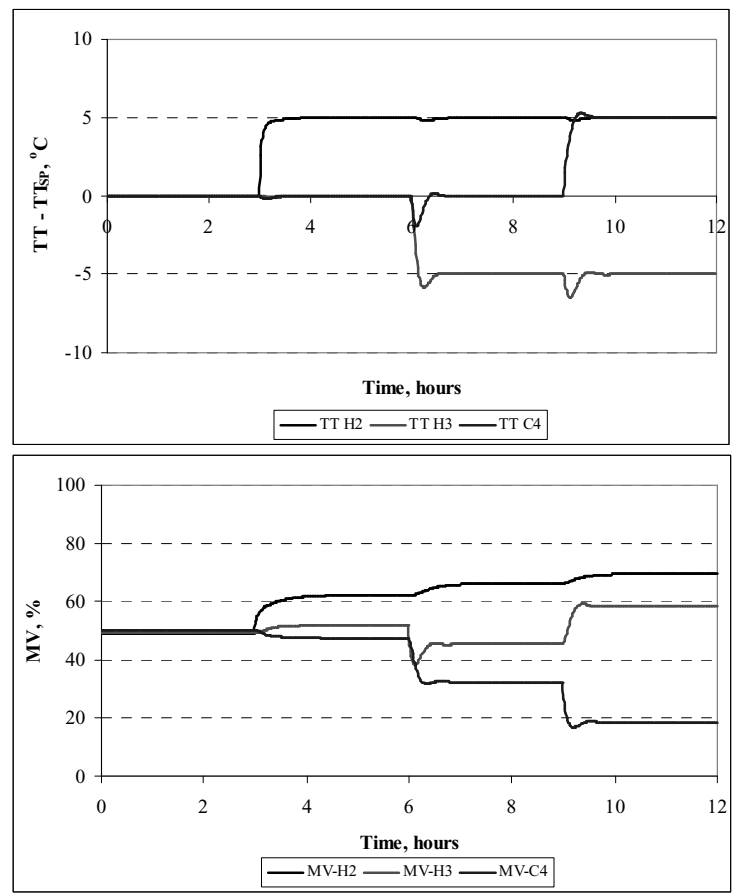

Fig. 4. Dynamic behaviour of HEN\#2 to set point changes 

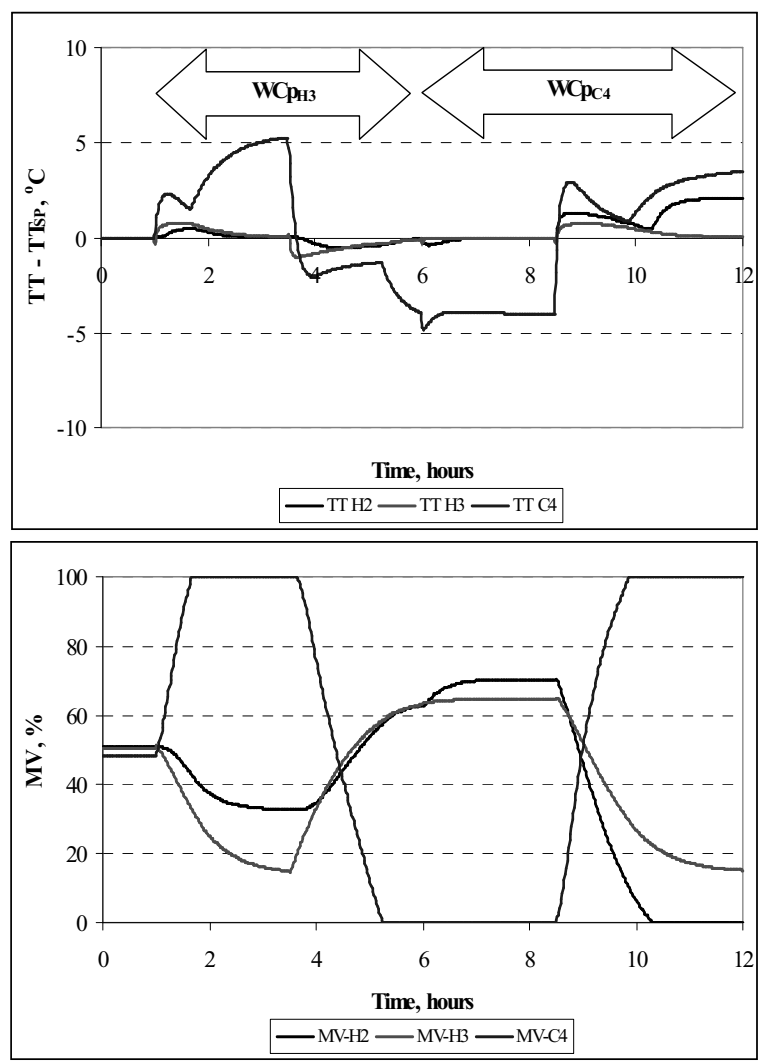

Fig. 5. Dynamic response of HEN\#1 to disturbances in $W C p_{\mathrm{H} 3}$ and $W C p_{\mathrm{C} 4}$
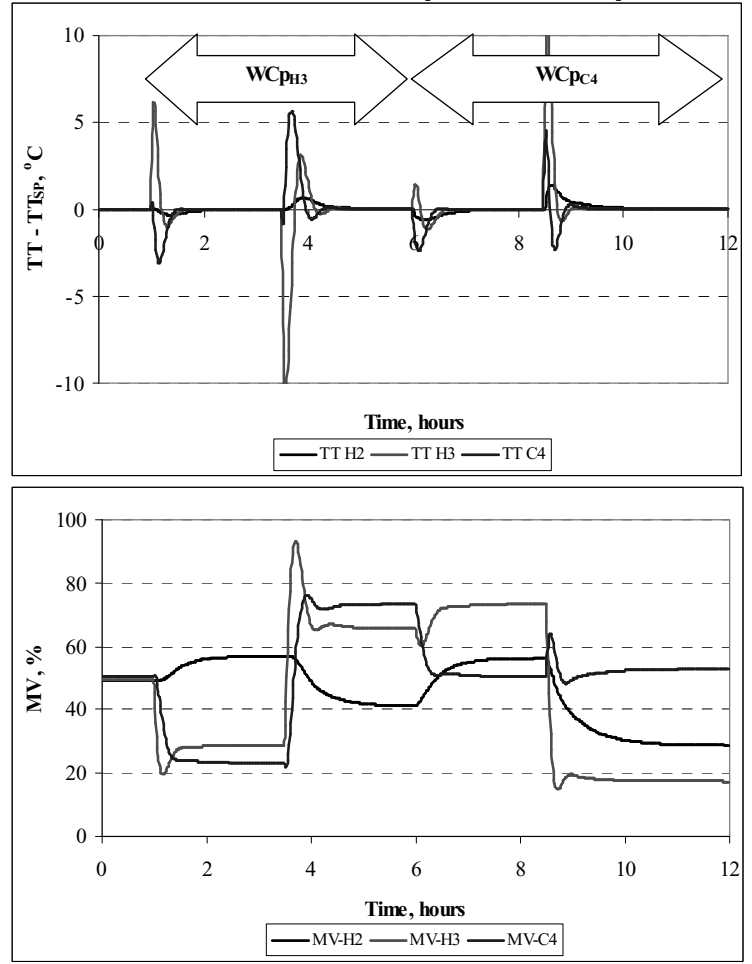

Fig. 6. Dynamic response of HEN\#2 to disturbances in $W C p_{\mathrm{H} 3}$ and $W C p_{C 4}$
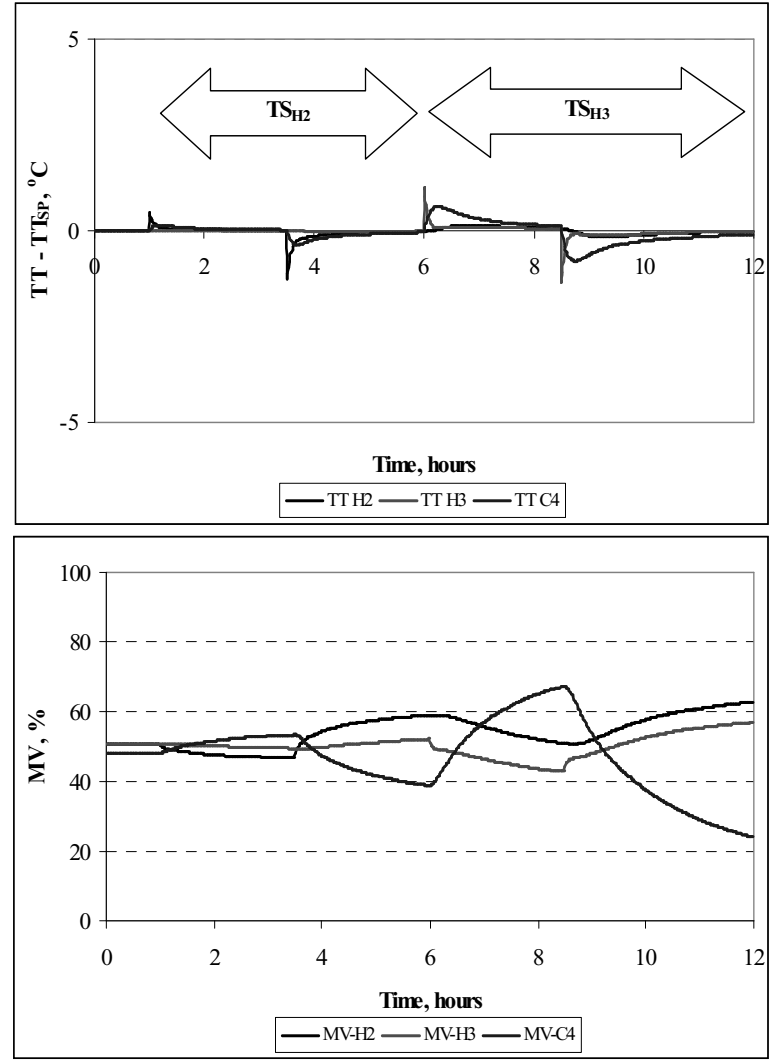

Fig. 7. Dynamic response of HEN\#1 to disturbances in $\mathrm{TS}_{\mathrm{H} 2}$ and $\mathrm{TS}_{\mathrm{H} 3}$
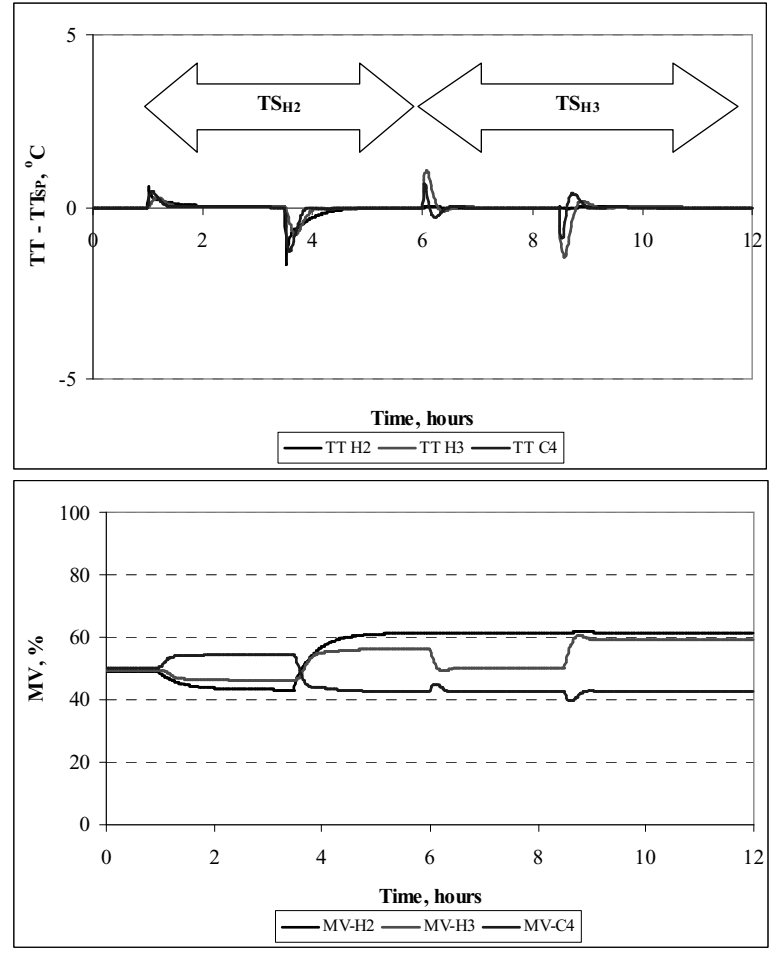

Fig. 8. Dynamic response of HEN\#2 to disturbances in $\mathrm{TS}_{\mathrm{H} 2}$ and $\mathrm{TS}_{\mathrm{H} 3}$ 